\title{
Prazer e sofrimento no trabalho: estudo com mulheres terceirizadas que atuam nos serviços gerais em uma Instituição Federal de Ensino Superior
}

Este estudo buscou descrever e analisar as vivências de prazer e sofrimento no trabalho de mulheres terceirizadas que atuam nos serviços gerais em uma Instituição Pública de Ensino Superior no estado de Minas Gerais. Com vista a atender os objetivos da pesquisa, foi realizada uma pesquisa descritiva com abordagem qualitativa. A coleta de dados se deu por meio de cinco entrevistas semiestruturadas com mulheres terceirizados que atuam na Instituição pesquisada. Os principais resultados apontaram que as entrevistadas consideram o seu trabalho prazeroso e tranquilo, possuindo tempo disponível para realização das tarefas. Com relação ao sentido do trabalho, as vivências de prazer se manifestam por meio dos incentivos, elogios e orgulho pelo trabalho realizado e recompensa financeira. As vivências de sofrimento foram manifestadas pelas cobranças excessivas, pela falta de reconhecimento, pelo monitoramento excessivo e a falta de liberdade para trabalhar. As mulheres utilizam estratégias individuais para lidar com a fiscalização e a cobrança por desempenho e procuram exercitar o autocontrole, desabafar com colegas do trabalho, relaxar e voltar-se para a família. Em se tratando de danos físicos, as entrevistadas sofrem com tendinite, problemas de coluna, problemas de circulação e hérnia de disco. Em termos de danos psicossociais, elas vivenciaram conflitos nas relações familiares ou sociais em decorrência da situação de trabalho.

Palavras-chave: Psicodinâmica do trabalho; Prazer no trabalho; Sofrimento no trabalho; Terceirização.

\section{Pleasure and suffering at work: study with outsourced women who work in the general services at a Federal Institution of Higher \\ Education}

\begin{abstract}
This study aimed to describe and analyze the experiences of pleasure and suffering in the work of outsourced women who work in the general services in a Public Institution of Higher Education in the state of Minas Gerais. In order to meet the research objectives, a descriptive research with a qualitative approach was carried out. The data collection was done through five semi-structured interviews with outsourced women who work in the Institution researched. The main results indicated that the interviewees considered their work to be pleasant and quiet, having time available to perform the tasks. About the meaning of work, the experiences of pleasure are manifested through incentives, praise and pride in the work done and financial reward. The experiences of suffering were manifested by excessive collections, lack of recognition, excessive monitoring and lack of freedom to work. Women use individual strategies to deal with performance monitoring and charging and seek to exercise self-control, venting with colleagues at work, relaxing, and turning to the family. When it comes to physical damage, the interviewees suffer from tendinitis, spinal problems, circulation problems and disc herniation. In terms of psychosocial damages, they experienced conflicts in family or social relationships as a result of the work situation.
\end{abstract}

Keywords: Psychodynamics of work; Pleasure at work; Suffering at work; Outsourcing.

Topic: Recursos Humanos

Reviewed anonymously in the process of blind peer.
Received: 10/05/2018

Approved: 17/07/2018
Josane Sodré Cupertino Silva

Centro Universitário Unihorizontes, Brasil

http://lattes.cnpq.br/0640079958335733

josanesodre@gmail.com

Fernando Coutinho Garcia

Universidade de São Paulo, Brasil

http://lattes.cnpq.br/4973183681192358

fernando.coutinho@unihorizontes.br

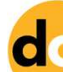

DOI: 10.6008/CBPC2179-684X.2018.002.0004
Referencing this:

SILVA, J. S. C.; GARCIA, F. C.. Prazer e sofrimento no trabalho: estudo com mulheres terceirizadas que atuam nos serviços gerais em uma Instituição Federal de Ensino Superior. Revista Brasileira de Administração Científica, v.9, n.2, p.36-49, 2018. DOI: http://doi.org/10.6008/CBPC2179-684X.2018.002.0004 


\section{INTRODUÇÃO}

Segundo Gómez (2002), no final do século XX, o mundo havia mudado, e o Estado precisava rever a relação Estado-sociedade. A Reforma Administrativa passou a ser prioridade para os governantes, visando à implementação de políticas para resgatar a capacidade do Estado de formular e avaliar as políticas no seu núcleo estratégico por meio da transição de uma administração burocrática rígida, inflexível e ineficiente para uma administração gerencial flexível, eficiente e voltada para o atendimento da cidadania e para o desenvolvimento econômico e social.

Nesse sentido, de acordo com Alves (2010), a terceirização de serviços na Administração Pública tem crescido muito nos últimos anos, em função dos avanços tecnológicos, do processo de gestão de pessoas e, em parte, pela necessidade de redução do quadro de pessoal. A terceirização é um instrumento utilizado para reduzir ou suprimir a participação do Estado em atividades não essenciais, como serviços de limpeza, pedreiros, cozinheiros, porteiros, vigilantes, entre outros, buscando a redução dos gastos públicos, o aumento da qualidade e a maior eficiência da máquina administrativa.

Para Antunes (2015), além das vantagens que justificam o crescimento do trabalho terceirizado, temos o outro lado pelo qual se constatam os riscos da prática da terceirização, que surgem durante a vigência do contrato. De acordo com Duarte et al. (2015), a gestão do trabalho implantada pelo medo da perda do emprego impõe a obrigatoriedade da multifuncionalidade, a execução de tarefas monótonas, repetitivas ou insignificantes, além de estabelecer a incerteza e proliferar a insegurança entre todos, propiciando o adoecimento. Para Dejours (2007), a cultura e o poder nas relações de trabalho permitem compreender as razões dos conflitos e dos constrangimentos provocados pelas relações do trabalho e o funcionamento psíquico do trabalhador.

Diante do contexto apresentado até aqui, este estudo busca responder à seguinte questão de pesquisa: como se configuram as vivências de prazer e sofrimento de mulheres terceirizadas que atuam nos serviços gerais em uma Instituição Federal de Ensino Superior?. Para responder à pergunta, colocou-se como objetivo descrever e analisar as vivências de prazer e sofrimento no trabalho de mulheres terceirizados que atuam em uma Instituição Pública de Ensino Superior no estado de Minas Gerais.

Este artigo está organizado em quatro seções, incluindo esta introdução. Na segunda, coloca-se o referencial teórico que embasa a pesquisa. Na terceira seção, aborda-se o percurso metodológico do estudo. Na quarta, apresenta-se a descrição e análise dos resultados da pesquisa. Na quinta, se tecem as considerações finais, discussões e sugestões sobre o estudo realizado. As referências bibliográficas consultadas para a pesquisa complementam o artigo.

\section{REVISÃO TEÓRICA}

A Psicodinâmica do Trabalho, abordagem desenvolvida por Christophe Dejours, começa a partir dos estudos da psicopatologia do trabalho, que tratava de colocar em evidência a clínica das doenças mentais e síndromes que poderiam ser ocasionadas pelo trabalho (DEJOURS, 2011b). Apesar de a Psicodinâmica do Trabalho desenvolver-se a partir da Psicopatologia do Trabalho, Christophe Dejours, médico francês 
responsável pelo Laboratório de Psicologia do Trabalho e da Ação, em Paris, França, constatou a necessidade de aprofundamento nos estudos, transformando a Psicodinâmica em uma disciplina autônoma, com seus próprios objetos, princípios, conceitos e métodos, na busca de compreender os conflitos entre a opressão provocada pela organização do trabalho e o funcionamento psíquico do trabalhador.

Entretanto, os estudos não evidenciavam adoecimento na maior parte dos trabalhadores, mas, sim, fatos que apontavam que, mesmo em contexto extremamente precários e desenvolvendo tarefas monótonas, repetitivas ou insignificantes, os trabalhadores encontravam-se em um estado de normalidade que sobressaía em relação ao adoecimento (DUARTE et al., 2015).

Para Moraes (2006), a psicodinâmica do trabalho permitiu mudar o foco dos estudos da patologia para a normalidade, ao se deparar com esse estado de comportamento nos trabalhadores submetidos a condições precárias do trabalho. A normalidade é o resultado do enfrentamento entre o sofrimento provocado pelos constrangimentos organizacionais e os mecanismos de defesa criados pelos indivíduos contra esse sofrimento (DEJOURS, 2011b).

Dejours considerava que a normalidade não significava estado saudável; poderia representar um sintoma de um estado patológico resultante de um equilíbrio precário, exercido pelo trabalhador para enfrentar a pressão das organizações e às custas de muito sofrimento (DUARTE et al., 2015). Para Moraes (2006), essa normalidade é expressa afetando a saúde mental do trabalhador, que, tendo inibida sua criatividade, sente-se alienado, oprimido, inabilitado fisicamente frente ao ritmo de trabalho imposto acima de sua capacidade. A cobrança das organizações visando à produção, o exercício de pressão psicológica dessas organizações sobre os trabalhadores, obrigando-os a apresentar conduta diversa, tolhendo-lhes a subjetividade e submetendo-os aos valores do capital, seriam os motivos que levam o trabalhador ao prejuízo da saúde mental.

Segundo Dejours et al. (1994), o trabalhador confronta-se no trabalho com angústias existenciais, impostas pelas restrições geradas pela organização do trabalho, que poderão the ocasionar sofrimento. Contudo, o ambiente de trabalho também é fonte de prazer, na medida em que permite ao indivíduo atualizar sua capacidade criativa e sublimatória. Dessa forma, a experiência psicossocial de prazer e sofrimento constrói o sentido do trabalho, trazendo, assim, equilíbrio psíquico ou adoecimento. Dessa forma, prazer e sofrimento são elementos centrais da Psicodinâmica do Trabalho para a observação dos processos de subjetivação e mobilização do indivíduo, estabelecendo o equilíbrio entre a saúde mental e a ocupacional. Esses elementos serão discutidos a seguir.

\section{Prazer e sofrimento no trabalho}

Para a Psicodinâmica do Trabalho, o prazer é considerado um dos elementos centrais para o estabelecimento do equilíbrio psíquico, estando a história de vida do trabalhador e as suas escolhas conscientes associadas ao contexto das relações de trabalho, sendo um caminho para evitar o sofrimento (DEJOURS et al., 1994). 
O prazer pode ser considerado como uma forma de o trabalhador aplicar uma descarga de energia psíquica que a tarefa autoriza, de modo que, se um trabalho permite a diminuição da carga psíquica, ele promove o equilíbrio do sujeito e proporciona prazer. Se os trabalhadores não conseguem fazer essas descargas, a energia psíquica se acumula, tornando-se fonte de sofrimento (DEJOURS et al., 1994; CASTRO et al., 2010).

Portanto, o prazer é vivenciado quando o trabalho favorece a valorização do reconhecimento, especialmente pela realização de uma tarefa significativa e importante para a organização e para a sociedade. O uso da criatividade e a possibilidade de expressar uma marca pessoal, o orgulho e a admiração pelo que se faz aliados ao reconhecimento da chefia e dos colegas, tornam-se fontes de prazer (FERREIRA et al., 2001).

O prazer se manifesta por meio da gratidão, da realização, do reconhecimento, da liberdade e da valorização do trabalho. O prazer pode ser experimentado quando a organização do trabalho é saudável, proporcionando ao trabalhador a liberdade de se estruturar e se adequar à sua tarefa, ajustar a realidade de trabalho a seus desejos e suas necessidades; quando existe a oportunidade de negociar e as relações socioprofissionais são democráticas e justas. Passa a ser possível, então, o processo de reconhecimento, prazer e transformação do sofrimento (MENDES, 2011). Dessa forma, para Dejours (2008b), o prazer contém indicadores de saúde no trabalho, por promover a estruturação psíquica, a identidade e a manifestação da subjetividade.

É perceptível, então, que o trabalho não é tido somente como fonte de prazer. Quando as relações interpessoais, as condições organizacionais do trabalho e a expressão da subjetividade não se encontrarem favoráveis ao trabalhador dentro das organizações, estas poderão causar sofrimento (MENDES et al., 2002). O termo sofrimento no trabalho, historicamente, tem suas origens nas obras de Freud (1976), que considera sofrimento diferente de doença, mas parte da vida humana. Foi a partir das concepções de Freud que Dejours (2011) infere ser o sofrimento inerente ao trabalho, pois ele surge de um conflito entre os desejos e as necessidades dos trabalhadores e as normas, leis, regras e prescrições das organizações, realidade que pode causar um desequilíbrio do funcionamento psíquico.

A Psicodinâmica do Trabalho entende que o conflito entre a organização do trabalho e o indivíduo é inevitável. Ela considera que há um conflito entre o mundo interno do trabalhador e o mundo externo, fazendo com que o confronto entre a organização do trabalho e o mundo interno e subjetivo do trabalhador seja um estímulo de sofrimento psíquico (DEJOURS, 1999; HELOANI et al., 2004).

Segundo Vasconcelos (2013), há situações em que os indivíduos, mesmo diante dos elementos de reprovação, da falta de cooperação, isolados e solitários, participam de situações que discordam intimamente, agindo de forma contrária a seus valores. Quando vivenciam essas situações que eles mesmos condenam moralmente, o sofrimento é manifestado através da insegurança, da vergonha, do medo e da angústia. Nesse caso, o sofrimento é denominado ético, ou seja, um conflito moral e emocional do indivíduo com ele mesmo.

O sofrimento se manifesta de forma diferente para cada indivíduo de uma mesma cultura, período ou família. Isso quer dizer que, ainda que submetidos às mesmas condições, os indivíduos tendem a perceber 
o sofrimento de maneira diferente. Assim, o que caracteriza sofrimento para um sujeito pode caracterizar prazer para outro. Prazer e dor podem estar combinados no sofrimento, pois este depende da significação que lhe é conferida pelo sujeito (BRANT et al., 2004; DEJOURS, 2008a; MORAES, 2013).

\section{A terceirização}

A terceirização no Brasil se efetivou na década de 1990, quando o país teve de se adequar a uma divisão de trabalho que buscava, cada vez mais, a especialização da produção de bens e serviços com menor valor agregado, com baixo conteúdo tecnológico e uso intensivo de mão de obra barata (POCHAMANN, 2008). Com foco nos custos, terceirizar representa, então, a "contratação de trabalhadores com remuneração e condições de trabalho inferiores aos postos de trabalho anteriormente existentes" (POCHMANN, 2012).

O mercado de trabalho brasileiro detém características particulares cuja explicação tem origem na entrada tardia no capitalismo. Podem-se destacar como principais características: o excedente estrutural de força de trabalho, a informalidade, a elevada rotatividade, as altas taxas de trabalho informal, os baixos salários e a larga desigualdade de renda, fazendo com que a relação entre empregador e empregado seja assimétrica (KREIN, 2007).

Segundo Pochmann (2012), para compreender o sentido da terceirização, é necessário olhar, primeiramente, para o contexto do mercado, por se tratar de um conceito surgido no campo da administração como forma de solucionar questões empresariais. No Brasil, a administração pública desenvolveu a terceirização pautada nos conceitos utilizados pela administração de empresas, ou seja, um conceito inerente ao mundo empresarial que foi transplantado no setor público.

No final do século XX, com as modificações ocorridas no setor socioeconômico, o Estado percebeu que era necessário se reestruturar para adaptar-se às atuais mudanças. A Reforma Administrativa passa, então, a ser indispensável para os governantes, pleiteando melhores resultados e com sua estrutura política voltada para as ações sociais e para o desenvolvimento econômico e social, mudando sua postura burocrática de administração dos interesses públicos para um novo modelo de gestão de atendimento à cidadania. (BRESSER-PEREIRA, 1998).

Nesse sentido, de acordo com Alves (2010), o Estado vem utilizando a terceirização como instrumento de redução do quadro de pessoal, transferindo a execução das atividades não essenciais para outras empresas, com o objetivo de aumentar a qualidade dos serviços prestados e a eficiência da máquina administrativa.

Com a coparticipação das organizações empresariais nas atividades complementares do Estado, o mercado da terceirização ganhou força, o que deu origem às primeiras empresas do ramo no setor público. As implicações da flexibilidade do trabalho são evidenciadas com a ampliação de vagas temporárias, mas, por outro lado, estimulam a fragilidade das organizações dos trabalhadores, com perdas de direitos e benefícios, reforçando a precarização e intensificação do trabalho (POSCHAMANN, 2008).

Para Morin (2001), a organização do trabalho pode influenciar no sentido que o trabalho tem para o trabalhador e na formação de sua identidade, pois tem o poder de modificar o comportamento das pessoas, 
causando mudanças nas atividades realizadas ou produzidas, no próprio indivíduo e no ambiente onde ele trabalha. $O$ trabalho repleto de sentido é aquele em que o sujeito tem liberdade e vontade de executá-lo.

Para Dejours (2008a), não existe trabalho apenas de execução, pois ele tem um sentido também para quem o executa. Nesse contexto, a psicodinâmica do trabalho tem o papel de compreender a relação homem-trabalho, bem como o que o sujeito deve acrescentar ao que foi prescrito pela organização para alcançar os objetivos individuais e coletivos e evitar o adoecimento no trabalho.

\section{METODOLOGIA}

A presente pesquisa pode ser classificada como sendo de natureza descritiva, com abordagem qualitativa e método adotado foi o de estudo de caso. Minayo (2007) explica que a pesquisa qualitativa busca responder a questões muito particulares e trabalha com profundidade elementos como valores, motivos, desejos e atitudes que constituem a realidade social. Portanto, essa pesquisa busca, por meio da abordagem qualitativa, identificar as percepções e expectativas mulheres terceirizados que atuam em uma Instituição Pública de Ensino Superior no estado de Minas Gerais, acerca de suas vivências de prazer e sofrimento no exercício de suas funções de conservação e limpeza. Já o estudo de casos é adotado como meio de subsidiar a investigação empírica, que, pela observação de um fenômeno atual, permite a descrição das características peculiares da população pesquisada (YIN, 2010).

Na concepção de Bardin (2009), a unidade de análise refere-se ao segmento pesquisado sobre o qual se coletam e analisam os dados. Sendo assim, a unidade de análise compreende por uma Instituição Federal de Ensino Superior situada na zona da mata do Estado de Minas Gerais. A instituição foi criada em 1922 e inaugurada em 28 de agosto de 1926, pelo governo do estado de Minas, adquirindo renome em todo o País, o que motivou o Governo Federal a federalizá-la, em 1969. Possui 48 cursos de graduação, 80 programas de Pós-Graduação, sendo13 lato sensu e 67 stricto sensu e um curso de Educação Aberta e a Distância. Para o funcionamento das atividades e atendimento aos estudantes que atualmente são 22.069 , a instituição conta com 1.324 docentes, 2.196 técnicos administrativos e 1.054 trabalhadores terceirizados.

Nesse estudo, os sujeitos de pesquisa foram cinco mulheres terceirizadas que atuam nos serviços gerais da Instituição pesquisada. Elas foram definidas por intencionalidade; ou seja, seleciona-se um subgrupo considerado representativo, cujos integrantes detêm as informações de interesse da pesquisa (GIL, 2008).

A coleta de dados aconteceu por meio de entrevistas semi-estruradas aos sujeitos pesquisados, o roteiro de entrevistas foi adaptado a partir do Inventário sobre o Trabalho e os Riscos de Adoecimento (ITRA), um instrumento quantitativo que foi validado por Mendes e Ferreira (2007). As entrevistas foram gravadas, transcritas e agrupadas conforme categorias selecionadas do ITRA.

Os dados foram analisados pela técnica de análise de conteúdo segundo os padrões de Bardin (2009). Para a autora esta técnica além de levar a compreensão da comunicação entre entrevistador e entrevistado, permite transcrever os conteúdos das mensagens, com informações críticas. Para a realização desta análise 
estabeleceu-se categorias de análise definidas a priori, sendo elas: contexto do trabalho, sentido do trabalho, estratégias para lidar com o sofrimento no trabalho e danos do trabalho.

Por meio desse procedimento de criação de categorias, serão estabelecidos os critérios a serem escolhidos para a análise do material. Posteriormente, será realizada uma seleção dos dados que serve para realizar uma atenuação do material a fim de selecionar somente os conteúdos mais relevantes pertinentes a cada categoria previamente determinada. A partir daí será possível a criação das subcategorias que emergirem dos depoimentos colhidos com os participantes da pesquisa.

\section{RESULTADOS E DISCUSSÃO}

O perfil das mulheres terceirizadas que participaram da pesquisa pode ser observado no quadro 1. No que tange ao perfil dos entrevistados, o quadro 1 mostra que todas entrevistadas são do sexo feminino, duas são casados, uma solteira, uma viúva e uma separada, com idade variando entre 36 a 56 anos, possui em sua maioria a escolaridade é ensino fundamental incompleto, atuando como terceirizadas entre 5 a 11 anos de trabalho.

Quadro 1: Perfil dos entrevistados.

\begin{tabular}{|c|l|c|l|c|c|}
\hline Entrevistado & Sexo & Idade (anos) & Estado Civil & Escolaridade & Tempo de trabalho como terceirizadas \\
\hline E1 & Fem. & 45 & Separada & Ensino Médio Completo & 8 anos \\
\hline E2 & Fem. & 48 & Casada & Ensino Fundamental Incompleto & 5 anos \\
\hline E3 & Fem. & 46 & Solteira & Ensino Fundamental Incompleto & 8 anos \\
\hline E4 & Fem. & 56 & Viúva & Ensino Médio Completo & 11 anos \\
\hline E5 & Fem. & 36 & Casada & Ensino Fundamental Incompleto & 5 anos \\
\hline
\end{tabular}

Para a análise dos dados, foram utilizadas algumas das dimensões do ITRA, compreendendo as categorias relacionadas ao contexto do trabalho, sentido do trabalho e danos do trabalho. Das categorias mencionadas, emergiram algumas subcategorias, sendo relevantes devido à representatividade para os entrevistados, conforme exposto no quadro 2.

Quadro 2: Categorias e subcategorias do conteúdo das entrevistas.

\begin{tabular}{|c|c|}
\hline CATEGORIAS & \multirow{2}{*}{ SUBCATEGORIAS } \\
\hline CONTEXTO DO TRABALHO & \\
\hline Organização do Trabalho & $\begin{array}{l}\text { - Trabalho prazeroso e tranquilo } \\
\text { - Tempo disponível para o trabalho } \\
\text { - Fiscalização e cobrança equilibrada }\end{array}$ \\
\hline Condições do Trabalho & $\begin{array}{l}\text { - Ambiente de trabalho } \\
\text { - Equipamentos utilizados } \\
\text { - Material de consumo }\end{array}$ \\
\hline SENTIDO DO TRABALHO & SUBCATEGORIAS \\
\hline Vivências de prazer & $\begin{array}{l}\text { - Incentivo, } \\
\text { - Elogios pelo trabalho desempenhado } \\
\text { - Orgulho pelo trabalho } \\
\text { - Recompensa financeira. }\end{array}$ \\
\hline Vivências de sofrimento & $\begin{array}{l}\text { - Cobranças excessivas } \\
\text { - Falta de reconhecimento } \\
\text { - Monitoramento excessivo } \\
\text { - Falta de liberdade para trabalhar }\end{array}$ \\
\hline Estratégias para lidar com o sofrimento no trabalho & $\begin{array}{l}\text { - Exercitar o autocontrole } \\
\text { - Desabafar com colegas do trabalho } \\
\text { - Relaxar } \\
\text { - Voltar-se para a família. }\end{array}$ \\
\hline
\end{tabular}




\begin{tabular}{|c|l|}
\hline DANOS DO TRABALHO & \multicolumn{1}{c|}{ SUBCATEGORIAS } \\
\hline \multirow{2}{*}{ Danos físicos } & $\begin{array}{l}\text { - Movimentos repetitivos } \\
\text { - Problemas de coluna } \\
\text { - Problemas de circulação } \\
\text { - Hérnia de disco }\end{array}$ \\
\hline Danos psicossociais & $\begin{array}{l}\text { - Conflitos nas relações familiares ou sociais } \\
\text { - Vontade de abandonar tudo }\end{array}$ \\
\hline
\end{tabular}

\section{Contexto de trabalho}

Com relação ao contexto do trabalho, a categoria referente a organização do trabalho, revelou que as entrevistadas consideram o trabalho prazeroso e tranquilo, no entanto consideram não ter o devido reconhecimento das atividades realizadas, conforme expresso nos relatos. A esse respeito Dejours (2012) e Lima (2013) explicam que o reconhecimento e a valorização impactam, de forma considerável, a identidade do indivíduo, sendo o profissional autor do processo de construção da sua subjetividade no trabalho, pois, ao mesmo tempo em que transforma o trabalho, é transformado por ele. Os autores defendem que o reconhecimento e a valorização são essenciais para a formação da identidade do trabalhador, servindo como mecanismos de motivação para o trabalho, uma vez que fazem parte da fonte de prazer no trabalho.

Eu gosto do meu trabalho. Sempre mexi com isso, né. E eu faço porque gosto de fazer. Procuro fazer da melhor maneira possível, né, mesmo que não tenha reconhecimento, mas me faz bem, eu me sinto realizada fazendo meu trabalho, sim (E1);

Gosto do que faço, só não é valorizado. Exige muito esforço da gente, né. Estou satisfeita com que eu faço, pena que não agrada uns e outros (E2);

É um trabalho bom, sossegado. Porque já fui dona de casa muitos anos, então me identifico com aquilo que eu faço. Faço como amor e com carinho porque eu gosto (E4).

Em relação ao tempo disponível para a realização das tarefas, as entrevistadas relataram ter o tempo apertado, no entanto já conseguiram adaptar a rotina diária. Os serviços são cobrados e fiscalizados por um encarregado e caso aconteça algo que não esteja descrito no contrato de trabalho, elas são conduzidas a assinar uma advertência.

Tem dia que o corpo da gente pede um descansozinho. Nós temos escala tem vez que aperta, mas dá conta. Somos fiscalizadas. Se fizermos alguma coisa muito errada assinamos advertência. Eu nunca assinei uma (E2);

Hoje com os anos que estou trabalhando eu aprendi a dividir as minhas tarefas, porque senão a gente não dá conta. Hoje eu sou fiscalizada e cobrada pelo encarregado da empresa. Mas já fui fiscalizada pelo chefe do departamento. Tem chefe de departamento que liga para a empresa, as vezes uma coisa tão pequena que poderia falar com a gente, mas prefere ligar para a empresa e reclamar. Recebemos cobrança dos dois lados (E4);

O tempo é bom. Eu dou conta de fazer o serviço. Vem o encarregado e olha se o serviço ficou do jeito que precisa ficar (E5).

A fiscalização do trabalho e a cobrança por desempenho acontece de forma equilibrada. Existe compreensão por parte do encarregado que realiza as fiscalizações, tendo em vista que reconhecem a extensa demanda diária de trabalho das entrevistadas, o que pode ser comprovado nos relatos. No que se refere a organização do trabalho, Morin (2001) explica que ela pode influenciar no sentido que o trabalho tem para o trabalhador e na formação de sua identidade, pois tem o poder de modificar o comportamento das pessoas, causando mudanças nas atividades realizadas ou produzidas, no próprio indivíduo e no ambiente onde ele trabalha. 
O trabalho repleto de sentido é aquele em que o sujeito tem liberdade e vontade de executá-lo. No que se refere às condições do trabalho, as entrevistadas consideram o ambiente físico difícil de ser limpo. Observou-se que fatores como objetos antigos, móveis pesados, materiais entelhados, extenso número de carteiras dificultam a limpeza e conservação de tais ambientes, como demonstram os relatos.

Quando me cobra e falam assim - quando você tiver um tempinho você faz aquilo e tal - aí eu falo que vou fazer sim, mas aí eu peço ajuda para dá conta de tudo. Se eu não der conta também peço que mande uma pessoa para me ajudar para manter a qualidade, para a pessoa ver que eu também não sou uma máquina. Eu procuro não esquentar a cabeça dependendo da situação. Eu não vou ser sem educação com as pessoas, eu procuro mostrar o que quero e tento fazer o outro entender que 'estou' ali para trabalhar não preciso de ser humilhada, entendeu. No final dá certo. A pessoa acaba entendendo (E1);

Pelo pessoal do departamento não sou cobrada, mas pelo encarregado sim. Mas como eles têm dificuldade de arrumar pessoas que queiram ficar neste local, então ele não me cobra muito, porque o local é grande. Não. Hoje não ligo de ser cobrada porque eu já expliquei para o encarregado que o lugar é grande que não dou conta e eles sabem disso, tanto que quando falei que não iria dar conta, eles disseram para eu fazer de vagar para eu não adoecer (E3);

Eu procuro fazer tudo direitinho. Nunca assinei uma advertência. A gente vai ajustando ao que é pedido. A gente tem que ver onde está errando ou sendo insuficiente para trabalhar em cima daquilo (E4);

A sala do chefe do departamento tem muitos objetos antigos, que precisa de cuidado e muito difícil de limpar. Os móveis são pesados e cheio de detalhes. Fico com medo de estragar. Às vezes fica difícil limpar os cantos (E1);

Tem salas que são fáceis de limpar. Outras não. Tem uma sala grande e cheia de mesas. Cada funcionário chega numa hora. Nunca sei qual mesa limpar primeiro. Tem também as salas do porão que são pequenas e entulhadas de móveis e arquivos e, por isso, são difíceis de limpar (E2);

Eu limpo salas de aula. São salas amplas com 60 carteiras móveis, de metal, piso emborrachado, além dos banheiros (E4);

Tem uniforme. $\mathrm{O}$ uniforme é bom. Nem sempre tem o material necessário que a gente necessita, né, mas a gente acaba aprendendo a lidar com isso, se vira, enfim dá para levar (E1);

Não são ruins. Mas poderiam ser melhores. Os produtos não são de melhor qualidade, então exige muito esforço físico da gente (E2);

$\mathrm{O}$ uniforme, as botas, as luvas são adequadas para a gente mesmo. $\mathrm{O}$ material de consumo podia ser melhor (E5).

Morin (2001) evidencia a importância das condições de trabalho favoráveis, pois permite que o indivíduo atualize sua capacidade criativa e sublimatória, ainda, o ambiente favorável permite o desenvolvimento das relações, ou seja, configura-se em um espaço em que os indivíduos se sentem pertencentes a um grupo local ou social.

\section{Sentido do trabalho}

No que se refere ao sentido do trabalho, na categoria vivências de prazer, observou-se que a identificação com o trabalho vem pelo incentivo, pelos elogios e pela recompensa financeira. As entrevistadas sentem-se motivadas em desempenhar um bom trabalho e anseiam pelo momento do pagamento, como pode ser comprovado nos depoimentos. 
Quando sou elogiada, mesmo que sobrecarregada eu me sinto feliz. Quando as pessoas não querem que eu seja transferida do departamento. A gente procura fazer a diferença (E1);

Como eu disse, eu sempre trabalhei com isso. Satisfeita nem tanto, a gente trabalha porque precisa, né. E graças a Deus a gente tem o trabalho, eu sinto feliz, incentivada (E3);

Eu gosto mais de limpar que cozinhar, então aqui eu 'estou' no lugar certo. Eu sinto feliz quando estou trabalhando no que gosto de fazer. Recebo meu dinheiro direitinho que me ajuda muito. E agradeço a Deus pelo meu trabalho (E4).

Nesse sentido, Antunes (2009) acrescenta que por meio do trabalho, o homem produz recursos para satisfazer suas necessidades, permanece no universo da reprodução biológica e busca formas de produção e reprodução da vida social. Outra vivência de prazer experimentada pelas entrevistadas refere-se ao orgulho pelo trabalho, elas sentem-se orgulhosas quando seus direitos são assegurados pelos supervisores, pelos resultados positivos do trabalho, bem como pelo reconhecimento profissional, como pode ser observado nos relatos.

Eu sinto muito orgulho do que faço, sim. Sinto realizada quando o pessoal do departamento não deixa eles (os supervisores) me transferir para outro local e falam que meu trabalho é bom (E1);

Eu tenho orgulho do que faço sim, porque tem gente que faz o trabalho por fazer, eu faço porque gosto de ver as coisas limpinhas e organizadas (E2);

Saber que as pessoas gostam do que faço (E3).

Identificou-se ainda, no que tange as vivências de prazer, que o sentimento de utilizado, reconhecimento e valorização são aspectos relevantes para manifestação de prazer no trabalho. As entrevistadas sentem-se assim, quando são requeridas na função, quando são elogiadas e percebem o retorno positivo do trabalho.

Eu me sinto feliz quando elogiam e falam que está bom, as pessoas não querem que eu saia do departamento, porque vão perder uma pessoa que sabe fazer o serviço e vai mandar uma pessoa que, de repente, não vá dá conta. Ninguém é insubstituível, mas a gente tenta fazer a diferença (E1);

Quando está tudo limpinho e as pessoas gostam (E2);

Quando recebo elogios. Eu recebo muitos elogios inclusive do meu encarregado (E4).

É importante destacar que as entrevistadas consideram a remuneração financeira e os benefícios recebidos como um fator motivacional do trabalho, o que leva a entender que elas não reconhecem totalmente o sentido do trabalho. '[...] Fico motivada quando recebo o pagamento e ele vem direitinho com todos os benefícios isso faz a diferença' (E4).

A esse respeito, Sandin (2013) explica que ninguém fica motivado se não enxergar o significado do seu trabalho, é preciso mostrar para o indivíduo como a competência dele está impactando o resultado da organização. No que tange ao sentindo do trabalho associado à categoria de vivências de sofrimento, identificou-se na percepção das entrevistadas, que a insatisfação no trabalho ocorre devido as cobranças por parte dos encarregados. Elas sentem-se monitora durante todo o dia de trabalho o que causa incomodo, falta de liberdade para trabalhar, além da irritação. Identificou-se ainda que se sentem inseguras quando o contrato de prestação de serviço está finalizando, pois por serem empregadas terceirizadas não tem certeza quanto ao seu futuro na instituição. 
Eu me sinto insatisfeita, às vezes, pelas cobranças que são feitas e que não é com todos os colegas. Sinto insegura e temerosa quando está terminando o contrato de prestação de serviço da empresa, todos são dispensados e não sabem se serão contratados (E1);

A gente anda insegura direto porque cada turma tem um encarregado, nós somos vigiadas todo tempo, sem contar que o pessoal do departamento também vigia a gente. A gente se sente insegura mesmo. Aqui a gente se sente um pouco presa, tem muito chefe e eu não me sinto muito à vontade com meu trabalho. Eu me sinto presa (E2);

No passado tinha muito medo e insegurança. Hoje sinto temerosa quando o contrato da empresa está para ser renovado. Eu vi colegas minhas recebendo o aviso prévio e que não precisavam mais voltar. Eu não gostei, mas como eu nunca assinei uma advertência, sabia que comigo aquilo poderia não acontecer (E4).

Com relação a falta de reconhecimento pelo esforço profissional, as entrevistadas verbalizaram que há pouca valorização no trabalho. Por se tratar de um serviço de limpeza, além da desvalorização, percebem que são discriminadas, tendo em vista que por vezes as pessoas não as cumprimentam e não conservam e respeitam o local que foi limpo, conforme demonstrado nos relatos ilustrativos:

É um trabalho que não é valorizado por mais que você faça o seu melhor. As vezes uma falha, por esquecimento, de pegar uma vassoura sem a luva, aí somos cobrados. E esse sentimento me faz infeliz, tem gente que não liga, mas eu ligo, sim (E2);

A gente fica triste, mas tem que trabalhar, né. A pessoa passa quase que em cima de você e nem sequer te dá um bom dia. As vezes a gente está limpando e a pessoa passa para lá passa para cá e não está nem aí (E3).

A gente é cobrada pelo encarregado pelo que deixa de ser feito, muitas vezes não é visto o que foi feito além (E4).

Conforme colocado por Anjos (2013), o sofrimento no trabalho, de maneira geral, tem relação com a organização do trabalho, sendo manifestado pela diminuição da autonomia dada ao empregado, divisão e padronização de tarefas e falta de reconhecimento entre outros. No que tange as estratégias para lidar com o sofrimento no trabalho, a partir dos relatos dos entrevistados pode-se identificar a utilização de estratégias individuais para lidar com a fiscalização e a cobrança por desempenho. Para tanto, elas procuram exercitar o autocontrole, desabafar com colegas do trabalho, relaxar e voltar-se para a família. Assim, as estratégias de defesas buscam proteger o psíquico do trabalhador, sobre o qual as organizações tentam exercer controle uma ação de impacto e nociva aos sujeitos (DEJOURS et al., 1994).

As estratégias utilizadas pelas entrevistadas são de cunho individual. A esse respeito, Dejours et al. (1990) explicam que tais estratégias são caracterizadas pelos mecanismos de defesa ligados ao sujeito singular, em que só ele pode exprimir e experimentar; outro indivíduo, em nenhum caso, tem como experimentar, pois, elas fazem parte das vivências subjetivas.

\section{Danos do trabalho}

No que tange aos danos do trabalho, analisou-se os danos físicos e psicossociais. Com relação aos danos físicos, foi possível identificar que os mais expressivos estão associados a tendinite, causada por movimentos repetitivos, problemas de coluna, problemas de circulação, bem como hérnia de disco. Neste aspecto, Lacaz (2000) evidencia que no ambiente organizacional, a qualidade de vida pauta-se na saúde do trabalhador, de modo extinguir a ocorrência de danos físicos, permitindo alusões positivas para a organização e empregados. 
Já tive tendinite. É muito peso que a gente carrega, movimento repetitivo, torce muito pano para limpeza e isso prejudica mesmo a agente (E1);

Eu tenho desgaste na coluna. Também sinto dores nos braços. O médico disse que é de esforço repetitivo. Eu sinto muitas dores (E3);

Já fiz cirurgia de varizes. Já fiquei afastada com dores por causa de hérnia de disco (E4).

No que tange aos danos psicossociais, identificou-se a presença de conflitos nas relações familiares ou sociais em decorrência da situação de trabalho. As entrevistadas disseram que mesmo tentando evitar acabam compartilhando conflitos do trabalho em casa, como pode ser observado nos relatos. Outro aspecto importante apontado pelas entrevistadas foi que, diante do que experimentam no trabalho, sentem vontade de largar tudo e mudar de profissão, no entanto lembram-se dos compromissos financeiros e da necessidade de trabalhar. Tais achados podem ser evidenciados nos relatos.

Eu creio que sim. Eu as vezes eu não consigo esconder, mas não está na gente. Acaba levando meus conflitos para casa. Eles dizem que não é certo, mas acaba transparecendo (E2);

Para casa eu não levo meus problemas. Não adianta. Mas, minha família percebe quando estou triste. Eu não falo e guardo para mim. Com as colegas, às vezes, eu falo (E3);

Às vezes na conversa em família a gente cita alguns exemplos de coisas que aconteceram com a gente ou com alguma colega no trabalho, mas no geral não fico guardando sentimentos porque não faz bem para gente (E4);

Já tive vontade, mas infelizmente não posso. A gente tem os compromissos, né, então não tem jeito. Escolheria sim, apesar de como falei que gosto do faça, antes de vir para cá eu trabalhei como secretária eu tinha vontade de trabalhar de novo como secretária (E1);

Ah, sim. Na mesma hora que penso em largar, penso no outro lado. Ainda mais se tiver uma continha para pagar. Aí penso mais ainda. Aí não tem jeito (E2);

Já. Quando me trocaram de lugar de trabalho. Eu estava toda adaptada e eles me trocaram. Eu chorei demais, quase um mês. Pedi para não ir, mas já estou aqui há 3 meses e não encontram ninguém para me substituir. Já pensei sim. Por causa das minhas dores. Eu gostaria de um trabalho mais parado. Mas agora idade não permite muita mudança (E3).

Simon et al. (2012) explica que quando os trabalhadores têm esse tipo de pensamento em relação ao trabalho, é possível inferir que eles não se ligaram e não se comprometeram emocionalmente com a organização. Portanto, não se importariam em abandoná-la caso necessário e se a permanência custasse seu bem-estar, produtividade e oportunidade de crescimento.

\section{CONSIDERAÇÕES FINAIS}

Este artigo teve por objetivo descrever e analisar as vivências de prazer e sofrimento no trabalho de mulheres terceirizadas que atuam nos serviços gerais em uma Instituição Pública de Ensino Superior no estado de Minas Gerais. Com vista a atender o objetivo do estudo, foi realizada uma pesquisa descritiva, com abordagem qualitativa e método de estudo de caso. A coleta de dados ocorreu por meio de cinco entrevistas com mulheres da referida instituição.

Com relação a caracterização dos entrevistados duas são casados, uma solteira, uma viúva e uma separada, com idade variando entre 36 a 56 anos, possui em sua maioria a escolaridade é ensino fundamental incompleto, atuando como terceirizadas entre 5 a 11 anos de trabalho. No que tange ao contexto do trabalho, a categoria referente a organização do trabalho evidenciou que as entrevistadas consideram o seu 
trabalho prazeroso e tranquilo, possuem tempo disponível para o trabalho. Os dados evidenciaram a respeito das condições do trabalho que o ambiente é difícil de ser conservado e limpado devido a objetos antigos, móveis pesados, materiais entelhados, extenso número de carteiras. Os instrumentos e equipamentos utilizados são bons, no entanto, poderiam ser melhores.

Com relação ao sentido do trabalho, as vivencias de prazer se manifestam por meio dos incentivos, elogios e orgulho pelo trabalho realizado. A recompensa financeira também foi evidência como um importante fator de prazer no trabalho. As vivências de sofrimento foram manifestadas pelas cobranças excessivas, pela falta de reconhecimento, pelo monitoramento excessivo e a falta de liberdade para trabalhar.

Com apoio nos dos relatos desses pontos, percebeu-se que as entrevistadas utilizam estratégias individuais para lidar com a fiscalização e a cobrança por desempenho, portanto, elas procuram exercitar o autocontrole, desabafar com colegas do trabalho, relaxar e voltar-se para a família. Quanto aos danos do trabalho, em se tratando de danos físicos, identificou-se, por meio desta pesquisa, que as entrevistadas sofrem com tendinite causada por movimentos repetitivos, problemas de coluna, problemas de circulação e hérnia de disco. Em termos de danos psicossociais, as entrevistadas vivenciaram conflitos nas relações familiares ou sociais em decorrência da situação de trabalho.

Este estudo contribuiu, de maneira acadêmica, por possibilitar e viabilizar discussões e maior compreensão da dinâmica prazer-sofrimento no trabalho, assunto de interesse de discentes na área de administração, sociologia, psicologia e outras. O desenvolvimento do estudo contribui também para ampliar o acervo do conhecimento sobre o tema terceirização.

Ressalta-se, como limitação da pesquisa, a dificuldade em mobilizar mulheres terceirizadas para conceder as entrevistas. Outro fator identificado, refere-se ao número de entrevista que se restringiu apenas a cinco entrevistas, bem como o método de estudo de casos que não permite que os dados analisados sejam generalizados. Sugere-se para estudos futuros, que a pesquisa seja realizada em outros setores da instituição, bem como a expansão do estudo em outras instituições de ensino, com vista a possíveis generalizações.

\section{REFERÊNCIAS}

ALVES, O. N.. Terceirização de Serviços na Administração Pública. Brasília: TCU, 2010.

ANJOS, A. C. Y.; ZAGO, M. M. F.. A experiência da terapêutica quimioterápica oncológica na visão do paciente. Revista Latino Americana de Enfermagem, v.14, n.1, p.33-40, 2006.

ANTUNES, R.. Adeus ao trabalho?: Ensaios sobre as metamorfoses e a centralidade do mundo do trabalho. São Paulo: Cortez, 2015.

BARDIN, L.. Análise de Conteúdo. Lisboa: LDA, 2009.

BRANT, L. C.; MINAYO-GOMEZ, C.. A transformação do sofrimento em adoecimento: do nascimento da clínica à psicodinâmica do trabalho. Ciência \& Saúde Coletiva, Rio de Janeiro, v.9, n.1, p.213-223, 2004.
BRESSER-PEREIRA, L. C.. A Reforma do Estado dos anos 90: Lógica e Mecanismos de Controle. Lua nova, n.45, p.49-95, 1998.

CASTRO, N. T.; TOLEDO, A. H. F.; ANDERY, A. M. N.. Tramas do cotidiano: a psicodinâmica do trabalho em um conselho tutelar. Psicologia: Ciência e Profissão, Brasília, v.30, n.3, p.662-675, 2010.

DEJOURS, C.. Inteligência prática e sabedoria prática: duas dimensões desconhecidas do trabalho. In: LANCMAM, S., ZNELWAR, L. I.. Christophe Dejours: da psicopatologia à psicodinâmica do trabalho. 3 ed. Rio de Janeiro: Fiocruz, 2011b. p.277-299.

DEJOURS, C.. Prefácio. In. MENDES, A. M.. Psicodinâmica do trabalho: teoria, método e pesquisa. São Paulo: Casa do Psicólogo, 2007. p.19-22. 
DEJOURS, C.. Sofrimento e prazer no trabalho: a abordagem pela psicopatologia do trabalho. In: LANCMAN, S.; SZNELWAR, L. I.. Christophe Dejours: da psicopatologia à psicodinâmica do trabalho. Rio de Janeiro: Fiocruz, 2008.

DEJOURS, C.. Trajetória teórico conceitual. In: LANCMAM, S.; ZNELWAR, L. I.. Christophe Dejours: da psicopatologia à psicodinâmica do trabalho. 3 ed. Rio de Janeiro: Fiocruz, 2011a. p.47-194.

DEJOURS, C.; ABDOUCHELI, E.; JAYET, C.. Psicodinâmica do trabalho: contribuições da escola dejouriana à análise da relação prazer, sofrimento e trabalho. São Paulo: Atlas, 1994.

DUARTE, F. S.; MENDES, A. M. B.. Da escravidão à servidão voluntária: perspectivas para a clínica psicodinâmica do trabalho no Brasil. Farol: Revista de Estudos Organizacionais e Sociedade, v.2, n.3, p.68-128, 2015.

FERREIRA, M. C.; MENDES, A. M.. Trabalho: Prazer ou sofrimento Caderno Opinião, Curitiba, v.4, n.813, mar. 2001.

FREUD, S. Além do Princípio do Prazer. Edição Standard Brasileira das Obras Psicológicas Completas de Sigmund Freud, Rio de Janeiro, v.18, p.77-154, 1976.

GIL, A. C.. Métodos e técnicas de pesquisa social. São Paulo: Atlas, 2008.

GÓMEZ, C. P.. Reforma administrativa no governo FHC: Documento de pesquisa. In: BRESSAN, S.. Reforma Administrativa. In: LAMOUIER, B.; FIGUEIREDO, R.. A era FHC: um balanço. São Paulo: Cultura, 2002.

HELOANI, R.; LANCMAN, S.. Psicodinâmica do trabalho: o método clínico de intervenção e investigação. Revista Produção, São Paulo, v.14, n.3, p.77-86, 2004.

KREIN, J. D.. Tendências recentes nas relações de emprego no Brasil: 1990-2005. Tese (Doutorado em Economia Aplicada) - Universidade Estadual de Campinas, Campinas, 2007.

LACAZ, F. A. C.. Qualidade de vida no trabalho e saúde/doença. Ciência saúde coletiva, Rio de Janeiro, v.5, n.1, p.151-161, 2000.

LIMA, S. C. C.. Reconhecimento no trabalho. In: VIEIRA, F. O.; MENDES, A. M.; MERLO, A. R. C.. Dicionário crítico de gestão e psicodinâmica do trabalho. Curitiba: 2013. p.351-356.
MENDES, A. M.. Prazer, reconhecimento e transformação do sofrimento no trabalho. In: MENDES, A. M.. Trabalho e saúde: o Sujeito entre emancipação e servidão. Curitiba: 2011. p.13-25.

MENDES, A. M.; FERREIRA, M. C.. Inventário sobre Trabalho e Riscos de Adoecimento - ITRA: instrumento auxiliar de diagnóstico de indicadores críticos no trabalho. In: MENDES, A. M. B.. Psicodinâmica do trabalho: teoria, método e pesquisas. São Paulo: Casa do Psicólogo, 2007. p.111-126.

MENDES, A. M.; MORRONE, C. F.. Vivências de prazersofrimento e saúde psíquica no trabalho: trajetória conceitual e empírica. In: MENDES, A. M.; BORGES, L. O.; FERREIRA, M. C.. Trabalho em transição, saúde em risco. Brasília: EdUnB, 2002.

MINAYO, M. C. S.. O desafio do conhecimento: pesquisa qualitativa em saúde. São Paulo: Hucitec, 2007.

MORAES, G. T. B.. Qualidade de vida no trabalho: um estudo sobre prazer e sofrimento em uma multinacional na cidade de Ponta Grossa (PR). Dissertação (Mestrado em Engenharia de Produção) - Universidade Tecnológica do Paraná, Ponta Grossa, 2006.

MORAES, R. D.. Estratégias defensivas. In: VIEIRA, F. O.; MENDES, A. M.; MERLO, A. R. C.. Dicionário crítico de gestão e psicodinâmica do trabalho. Curitiba: 2013.

MORIN, E. M.. Os sentidos do trabalho. Revista de Administração de Empresas, São Paulo, v.41, n.3, p.8-19, 2001.

POCHMANN, M.. Nova classe média?: O trabalho na base da pirâmide social. São Paulo: Boitempo. 2012.

POCHMANN, M.. O emprego no desenvolvimento da nação. São Paulo: Boitempo, 2008.

SIMON, J.; COLTRE, S. M.. O comprometimento organizacional afetivo, instrumental e normativo: estudo de caso de uma empresa familiar. Qualitas, v.13, n.1, p.4-23, 2012.

VASCONCELOS, L. C. A.. Sofrimento ético. In: VIEIRA, F. O.; MENDES, A. M.; MERLO, A. R. C.. Dicionário crítico de gestão e psicodinâmica do trabalho. Curitiba: 2013.

YIN, R. K.. Estudo de caso: planejamento e métodos. Porto Alegre: Bookman, 2010.

A CBPC - Companhia Brasileira de Produção Científica (CNPJ: 11.221.422/0001-03) detém os direitos materiais desta publicação. Os direitos referem-se à publicação do trabalho em qualquer parte do mundo, incluindo os direitos às renovações, expansões e disseminações da contribuição, bem como outros direitos subsidiários. Todos os trabalhos publicados eletronicamente poderão posteriormente ser publicados em coletâneas impressas sob coordenação da Sustenere Publishing, da Companhia Brasileira de Produção Científica e seus parceiros autorizados. Os (as) autores (as) preservam os direitos autorais, mas não têm permissão para a publicação da contribuição em outro meio, impresso ou digital, em português ou em tradução. 